DOI: $10.5007 / 2175-7941.2013 v 30 \mathrm{n} 1 \mathrm{p} 25$

\title{
EXPERIÊNCIAS EMOCIONAIS DE ESTUDANTES DE GRADUAÇÃO COMO MOTIVAÇÃO PARA SE TORNAREM PROFESSORES DE FÍSICA ${ }^{+*}$
}

\author{
José Francisco Custódio \\ Departamento de Física - UFSC \\ Florianópolis - SC \\ Maurício Pietrocola \\ Departamento de Metodologia do Ensino e Educação Comparada - USP \\ São Paulo - SP \\ Frederico Firmo de Souza Cruz \\ Departamento de Física - UFSC \\ Florianópolis - SC
}

\section{Resumo}

Há, recentemente, na Educação Científica um crescimento da consciência coletiva sobre a influência dos aspectos afetivos na atividade intelectual dos indivíduos, em particular, na aprendizagem e na tomada de decisões. Neste trabalho, investigamos a influência da dimensão afetiva na decisão de seguir a carreira de professor de Física em acadêmicos da Universidade do Estado de Santa Catarina e da Universidade de São Paulo. A pesquisa foi orientada pelas seguintes questões: (1) Qual a influência da dimensão afetiva na decisão de seguir a carreira de professor de Física? (2) Quais são as principais experiências emocionais que motivam a escolha da carreira de professor de Física?(3) Quais eventos originam essas experiências emocionais? Foram investigados, por

\footnotetext{
Emotional experiences of undergraduate students as motivation to become Physics teachers

* Recebido: julho de 2012.

Aceito: janeiro de 2013.
}

Cad. Bras. Ens. Fís., v. 30, n. 1: p. 25-57, abr. 2013. 
intermédio de um questionário, 68 licenciandos em Física. Nossos resultados evidenciaram que as experiencias emocionais positivas e do interesse dos acadêmicos pesquisados formaram parte importante de suas motivações para se tornarem professores de Física. Utilizamos o modelo atribuição-expectativa de Silvia (2006) para explicar como tais experiências momentâneas contribuíram para formação de interesses duradouros nos sujeitos pesquisados.

Palavras-chave: Experiências emocionais. Ensino de Física. Atitudes. Interesse. Atribuição. Professor de Física.

\begin{abstract}
Recently, in the Science Education community, it has been a growing collective concern about the influence of affective aspects on the intellectual activity of individuals, particularly, in learning and making decision. In this study, we investigate the influence of the affective dimension in the decision to pursue the Physics teacher carrier by undergraduates of Santa Catarina State University and São Paulo University. The research was guided by the following questions: (1) What influence the affective dimension has in the decision to pursue a career as Physics teacher? (2) What are the key emotional experiences that motivate the choice of career as Physics teacher? (3) What events drive these emotional experiences? Those issues were investigated through a questionnaire applied to 68 undergraduates in Physics. Our results showed that positive emotional experiences and the interest of undergraduates formed an important part of their motivations to become physics teachers. We use Silvia's model attributionexpectative to explain how such momentary experiences contributed to develop a lasting interest on the subjects studied.
\end{abstract}

Keywords: Emotional experiences. Physics teaching. Attitudes. Interest. Attribution. Physics teacher. 


\section{Introdução}

A Física como disciplina no Ensino Médio gera reações variadas, mas sempre muito carregadas de emoção: tanto reações de aversão e ódio quanto o despertar de interesses duradouros que levam às escolhas profissionais. Mesmo no Ensino Superior, os cursos e as disciplinas de Física também têm um forte impacto nas reações dos estudantes. Até aqueles com um bom desempenho e uma boa formação no Ensino Médio se sentem desafiados diante de um novo contrato didático e diante de uma Física que lhes parece familiar, mas que exige novas formas de pensar, novas linguagens, novas interpretações e novas formas de enfrentamento. No caso específico do curso de Física, na maioria das universidades, os estudantes ingressantes são poucos e nem sempre obtiveram formação sólida em ciências e matemática no Ensino Médio. Isto é, um número significativo deles entra nos cursos de Física visando a uma outra carreira, como a Engenharia, enquanto que a parcela restante escolhe a Física com objetivos tanto de se tornar um professor quanto um pesquisador. Em qualquer um dos casos, esses estudantes podem vir a desenvolver ou manter um interesse duradouro pela Física, conforme mostram certos casos de persistência de alunos, inclusive com baixo desempenho acadêmico. O número reduzido de interessados em ingressar no curso, a grande evasão, o número baixo de formandos e a necessidade da sociedade e do país de profissionais na área da Física tem sido objeto de diferentes projetos e também de investigações na área de ensino de Física. Boa parte desses projetos tem uma abordagem mais cognitivista visando a novas formas de ensinar e de desenvolver o conteúdo de Física, ou de identificar e trabalhar obstáculos à aprendizagem. Neste trabalho, tem-se como ponto de partida a hipótese de que a formação de interesses duradouros não se remete apenas a aspectos cognitivos, mas a aspectos subjetivos de natureza emocional e afetiva que dão estímulo aos sujeitos de superarem os desafios para alcançar os objetivos de interesse.

Há, recentemente, na Educação Científica um crescimento da consciência coletiva que aspectos afetivos influem significativamente na atividade intelectual dos indivíduos, em particular, na aprendizagem (PINTRICH et al., 1993; TYSON et al., 1997; ALSOP; WATTS, 1997, 2000; VILLANI; CABRAL, 1997; PIETROCOLA; 2001; ALSOP, 2005). Essa reorientação se deve, em parte, às críticas decorrentes dos resultados pouco satisfatórios alcançados por abordagens extremamente cognitivistas (VILLANI, 1992; MORTIMER, 1995). Os proponentes desse novo empreendimento defendem que, na educação científica, haja uma apreciação adequada das conexões entre componentes afetivos e cognitivos na atividade relativa à construção dos conhecimentos, pelos alunos. Por exemplo, Gómez- 
Chacón (2003a), ao tratar a relação afeto-cognição, sugere que os afetos formam um sistema regulador da estrutura de conhecimento do aluno. Portanto, não basta que ele conheça de maneira apropriada os fatos, os algoritmos e os procedimentos para ter garantia de sucesso.

Todavia, ainda é relativamente pequena a quantidade de trabalhos na literatura sobre educação científica que têm sido explicitamente endereçados à detecção de sentimentos ou emoções (REISS, 2005). Boa parte da pesquisa sobre emoções aborda o tópico dentro de categorias gerais como atitudes sobre ciências, incluindo-as como subcategoria. De acordo com Osborne, Simon e Collins (2003), atitudes sobre ciências são os "sentimentos, crenças e valores criados sobre um objeto que pode ser a empresa científica, a ciência escolar, o impacto da ciência sobre a sociedade ou os próprios cientistas" (p. 1053). Nieswandt (2005) afirma que as atitudes sobre ciências se referem a "se uma pessoa gosta ou não gosta de ciências, ou tem um sentimento positivo ou negativo sobre ciências" (p. 42). Em geral, atitudes são entendidas como a composição de três elementos: um cognitivo, que se manifesta nas crenças implícitas sobre um objeto; um componente afetivo, que se manifesta nos sentimentos de aceitação ou de repúdio ao objeto; e um componente intencional ou de tendência a certo tipo de comportamento (GÓMEZCHÁCON, 2003b; NIESWANDT, 2005).

Atitudes sobre ciência têm sido investigadas nos mais diversos aspectos. Um dos focos de grande atenção é o interesse por ciência. Kahle e Lakes (1983), por exemplo, mostraram que as crianças, na maioria dos países, entram no Ensino Médio com atitudes altamente favoráveis sobre Ciência e interesse em Ciência, porém ambos são corroídos pela sua experiência com a ciência escolar. Resultados atuais continuam sistematicamente aumentando as evidências do declínio do interesse por ciência ao longo do processo de escolarização de jovens estudantes (BARAM-TSABARI; YARDEN, 2005; KRAPP; PRENZEL, 2011). Assim, alguns estudos trataram das atitudes sobre ciências e suas relações com a variável gênero (DAWSON, 2000; BUCCHERI; GURBER; BRUHWILER, 2011), enquanto outros se dedicaram à compreensão da influência de fatores sociais, fatores curriculares ou o tipo de instrução conduzido em sala de aula (SUNDBERG; DINI; LI, 1994). Finalmente, diversos pesquisadores têm olhado para fatores por detrás das expectativas dos alunos com relação à escolha de carreiras científicas ou relacionadas à ciência (PARK; KHAN; PETRINA, 2009; KJAERNSLI; LIE, 2011).

Uma vez que os estudantes de ciências são futuros candidatos a seguir carreiras científicas ou relacionadas à ciência, como a docência de Física, o declínio do interesse em ciências é um fator preocupante para o próprio desenvolvimento do país. Oon e Subramaniam (2011) argumentam que o baixo envolvimento em 
Física no nível universitário tem diretas consequências na construção da expertise tecnológica em um país; e consequências negativas que podem incluir a séria falta de talentos para indústria, para a área da tecnologia baseada em ciência e de professores de Física bem qualificados. Um reflexo disso já é sentido no cenário brasileiro, conforme atesta o relatório Escassez de Professores no Ensino Médio: Propostas Estruturais e Emergenciais, elaborado por comissão especial instituída no âmbito do Conselho Nacional de Educação (RUIZ; RAMOS; HINGEL, 2007). Dados desse relatório apontam para uma necessidade de cerca de 235 mil professores para o Ensino Médio no país, particularmente nas disciplinas de Física, Química, Matemática e Biologia. Precisa-se, por exemplo, de 55 mil professores de Física; mas, entre 1990 e 2001, só saíram dos bancos universitários 7.216 professores nas licenciaturas de Física.

Quais as razões desta escassez? Embora essa seja uma questão relevante, poucos estudos têm procurado compreender os fatores desencadeadores do baixo número de egressos dos cursos de licenciatura em Física. Por exemplo, Gobara e Garcia (2007) realizaram um levantamento da quantidade de professores disponibilizados pelas instituições formadoras entre 2001 e 2005, elencando como principais causas da carência de docentes o abandono do curso para inserção no mercado de trabalho, as dificuldades econômicas no período do curso, as expectativas negativas quanto à futura renda e o declínio do status social da profissão. Em outro tipo de análise, Borges (2006) apontou possíveis melhoramentos na qualidade da formação inicial dos professores como aspecto indissociável da necessidade de formar mais docentes. Diferentemente da tradição de atitudes sobre ciências, cujo enfoque está voltado para os futuros candidatos às carreiras científicas e suas expectativas, nesse último tipo de análise, o foco é a compreensão dos problemas enfrentados pelos docentes em seu período de graduação ou no exercício profissional, estabelecendo-se razões para a baixa quantidade de egressos e abandono do curso ou da profissão.

Neste trabalho, adotaremos uma posição intermediária, embora mais alinhada com a primeira perspectiva. Em vez de tratarmos das expectativas e dos interesses de alunos do Ensino Médio ou dos abandonos do curso ou da profissão, investigaremos a influência da dimensão afetiva na decisão de seguir a carreira de professor de Física de acadêmicos da Universidade do Estado de Santa Catarina e da Universidade de São Paulo. Isso, a nosso ver, dará um substrato mais amplo sobre os tipos de relação que levam um indivíduo a escolher a docência de Física, pois, se compreendermos as influências reais das escolhas, e não apenas tendências, como apontam os estudos em atitudes sobre ciências, poderemos definir caminhos, em termos de práticas educacionais, capazes de sensibilizar mais 
candidatos ao exercício do magistério. Consideramos que as atitudes desenvolvidas por estudantes com relação à ciência são fatores determinantes na escolha de carreiras ligadas à ciência, inclusive a docência; estamos de acordo que essas atitudes englobam o conteúdo emocional despertado pela ciência no indivíduo e uma série de comportamentos decorrentes, conforme sugerem Bybee e McCrae (2011):

O componente emocional das atitudes das pessoas sobre ciência se refere aos sentimentos evocados pela ciência. Ela é agradável ou desagradável? Gostei ou não gostei? Finalmente, existe um componente comportamental nas atitudes das pessoas sobre a ciência. O que o indivíduo irá ou não fazer? Irá o indivíduo apoiar empreendimentos cientificos? Estará interessado em perseguir uma carreira cientifica? (p. 12).

Todavia, nossa metodologia será distinta das usualmente realizadas por estudos que buscam identificar atitudes sobre ciências. Em geral, esses estudos têm sido conduzidos com a utilização de uma série de questões ou tópicos preparados, nos quais os indivíduos escolhem opções em escalas tipo Likert. Em contraste, nós pretendemos uma abordagem naturalística por intermédio de questões que explorem a importância da dimensão afetiva nas escolhas dos acadêmicos. Desejamos, assim, explorar explicitamente os sentimentos e as emoções envolvidos no processo. A pesquisa foi orientada pelas seguintes questões:

(1) Qual a influência da dimensão afetiva na decisão de seguir a carreira de professor de Física?

(2) Quais são as principais experiências emocionais que motivam a escolha da carreira de professor de Física?

(3) Quais eventos originam essas experiências emocionais?

\section{Metodologia}

Para identificarmos e analisarmos as motivações de licenciandos para se tornarem professores de Física e qual sua relação com suas experiências emocionais, utilizamos como instrumento de coleta de dados um questionário, a fim de obtermos dados tanto qualitativos quanto quantitativos. O principal propósito do questionário foi desenvolver, por intermédio de uma metodologia qualitativa descritiva e interpretativa da análise do conteúdo das respostas dos acadêmicos, uma profunda compreensão das suas percepções sobre a escolha pela carreira de professor de Física. 
O questionário era composto por três questões (vide apêndice 1). A primeira explorava as motivações gerais dos acadêmicos para ensinar Física e, em particular, se essa motivação estava conectada aos conhecimentos de Física. A segunda direcionava-se a investigar a influência da curiosidade e da emoção no interesse pela busca de explicação sobre o mundo natural e artefatos, e sobre a escolha dos acadêmicos. A terceira mostra um texto indutor, com o relato de uma experiência emocional de um professor de Física, a partir do qual se buscou evocar nos licenciados a lembrança de explicações significativas, quais sentimentos eles experimentaram com elas e como motivaram a escolha pela carreira de professor de Física.

\section{II.1 Amostra}

Responderam ao questionário completo, no semestre 2006/1, dezoito alunos da terceira fase do Curso de Licenciatura em Física da Universidade do Estado de Santa Catarina. Responderam às questões 1 e 2 do questionário, cinquenta licenciandos em Física das turmas de Metodologia do Ensino de Física I e II da Universidade de São Paulo, dos semestres 2005/02 e 2006/01.

\section{II.2 Análises}

Os dados foram analisados em processo interativo caracterizado por duas fases: (1) Extração das narrativas dos acadêmicos referente às cargas afetivas relacionadas com as escolha da carreira de professor de Física; (2) descrição e análise das experiências emocionais dos acadêmicos, segundo duas categorias: Experiência emocional positiva e experiência emocional do interesse. A segunda fase envolveu os seguintes passos: (a) Diversas leituras detalhadas das narrativas dos acadêmicos; (b) codificação de extratos das narrativas em categorias básicas de significado (por exemplo, "interesse de saber como as coisas funcionam", "satisfação de entender a parte de movimento relativo"); (c) inclusão das categorias básicas de significado nas duas categorias mais amplas de experiências emocionais que emergiram dos dados.

\section{Resultados}

\section{III.1 Cargas afetivas}

Segundo Campos e Rouquete (2003), cargas afetivas são os componentes afetivos das representações que os indivíduos produzem a respeito de um objeto. A 
fim de identificar as cargas afetivas associadas à motivação dos acadêmicos em se tornarem professores de Física, nós contamos, considerando apenas uma citação para cada narrativa, as palavras afetivas mencionadas. Para identificarmos se as palavras realmente se referiam a experiências afetivas, tomamos como referência Russell et al. (1995) e Shaver et al. (1987). Esses autores defendem uma perspectiva prototípica para classificação das emoções. A abordagem prototípica baseia-se na construção de protótipos a partir de emoções citadas, em termos cotidianos, envolvidas em episódios reais; isto é: considera que as emoções são compreendidas com referência a emoções prototípicas. Finalmente, sugere que a codificação inicial de um episódio emotivo ocorre, provavelmente, no nível básico da hierarquia emotiva. Por exemplo, neste modelo, satisfação encontra-se em um nível inferior dentro da emoção alegria, da mesma maneira que entusiasmo, porém alguém pode estar satisfeito sem estar entusiasmado, entretanto, nos dois casos, a emoção alegria estará presente. Então, todo trabalho dos pesquisadores dessa tradição se inicia com uma lista de palavras afetivas.

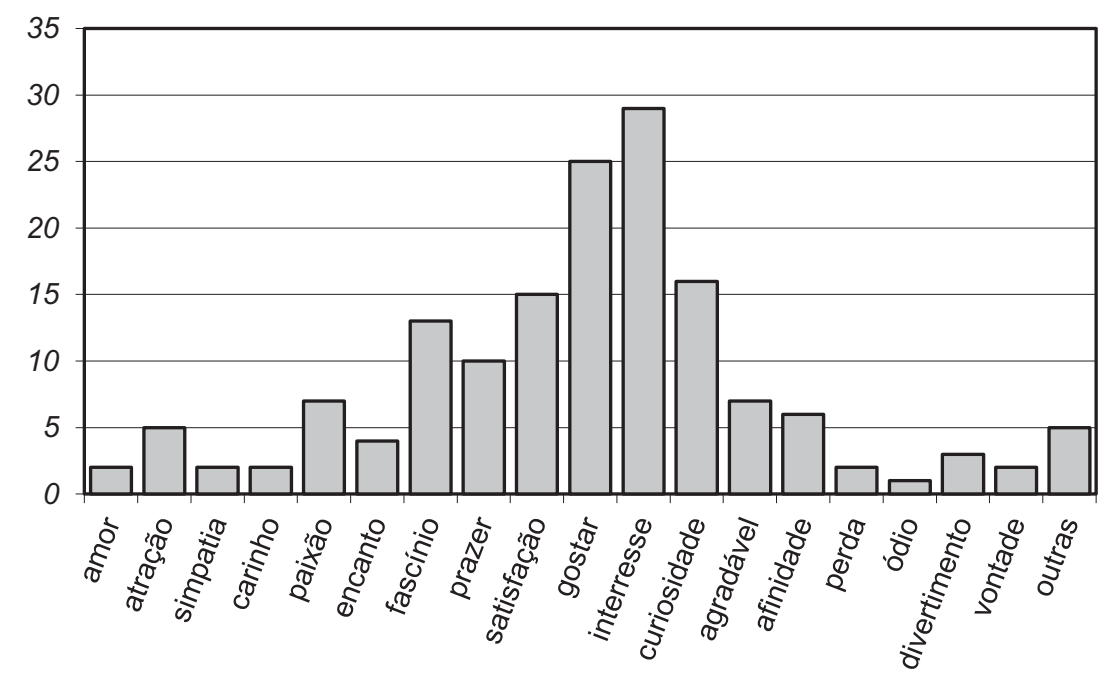

Fig. 1 - Frequência das palavras afetivas.

Foram encontradas cento e cinquenta e cinco ocorrências que fazem referência à afetividade e correspondem a vinte e três palavras diferentes. A Fig. 1 mostra as contagens individuais para as palavras. Interesse foi a palavra afetiva citada mais frequentemente, ocorrendo vinte e nove vezes. As seguintes palavras afetivas citadas mais frequentemente foram: gostar, com vinte e cinco citações; e 
curiosidade, com dezesseis citações. Palavras afetivas referentes a estados negativos praticamente não foram citadas; perda e ódio foram as exceções, com 2 e 1 ocorrências, respectivamente. As demais palavras afetivas oscilaram com frequências intermediárias.

A fim de identificar os tipos de emoções mencionadas, procuramos codificar as palavras afetivas em termos de emoções básicas. Existem muitas listas. A lista de Izard (1977) inclui interesse, alegria, surpresa, angústia, raiva, medo, vergonha, desgosto, desrespeito e culpa. Ekman (1984) sugere: medo, raiva, surpresa, desgosto, tristeza e felicidade. A lista de Epstein (1984) inclui medo, raiva, tristeza, alegria, amor e afeição. Shaver et al. (1987) incluem amor, alegria, surpresa, raiva, tristeza e medo. Damásio (2005) considera emoções inatas: medo, raiva, alegria, tristeza e nojo. Com base nessas listas, em particular na abordagem prototíicica de Shaver et al. (1987), distribuímos as palavras afetivas citadas nos episódios descritos pelos participantes do estudo em cinco classes de emoções: amor, alegria, raiva, interesse e tristeza. Embora não estivesse coberta em nenhuma das listas acima, a palavra curiosidade foi inserida na emoção interesse, pois, conforme Silvia (2006), "nenhuma evidência sugere diferenças entre interesse e curiosidade, então considera-los iguais é justificável" (p. 191). Adicionalmente, dividimos as emoções em termos de emoções positivas (amor e alegria), emoções negativas (tristeza e raiva) e emoção interesse (interesse).

Tabela 1 - Classificação e frequência das emoções.

\begin{tabular}{l|l|l|l|l}
\hline \multicolumn{2}{l|}{ Emoções positivas (101) } & Emoção interesse (46) & \multicolumn{2}{c}{ Emoções negativas (3) } \\
\hline Alegria (52) & Amor (49) & Interesse (46) & Tristeza (2) & Raiva (1) \\
\hline Satisfação & Amor & Interesse & Perda & Odio \\
\hline Agradável & Paixão & Vontade & & \\
\hline Prazer & Atração & Curiosidade & & \\
\hline Divertimento & Gostar & & & \\
\hline Encanto & Simpatia & & & \\
\hline Fascínio & Carinho & & & \\
\hline & Afinidade & & & \\
\hline
\end{tabular}

A tabela 1 mostra a distribuição das palavras afetivas segundo os tipos de emoção e a frequência das emoções. Alegria foi a emoção mais frequentemente 
mencionada, ocorrendo cinquenta e duas vezes, com seis diferentes palavras referindo-se a tal estado emocional. A segunda classe de emoção mais frequentemente mencionada foi amor, ocorrendo quarenta e nove vezes, com sete palavras diferentes. Interesse aparece como a terceira emoção mais frequente, com quarenta e seis ocorrências, em três palavras afetivas distintas. Finalmente, as emoções tristeza e raiva, ocorreram duas e uma vez, respectivamente.

Inúmeros trabalhos teóricos e empíricos mostram que emoções podem ser descritas em duas dimensões independentes (MANO; OLIVER, 1993; FREDRICKSON, 1998). A primeira, o afeto positivo, reflete a extensão na qual uma pessoa sente-se prazerosamente engajada com o ambiente, ativa mentalmente, alerta e determinada. A segunda, o afeto negativo, é um fator geral de angústia subjetiva e engajamento desprazeroso que envolve raiva, desprezo, desgosto, culpa, medo e nervosismo (WATSON et al., 1988). Então, nós codificamos, ainda, as emoções nas dimensões: positiva, incluindo as emoções amor e alegria, e negativa, incluindo as emoções tristeza e raiva. A emoção interesse, embora seja classificada como uma emoção positiva (SILVIA, 2006), foi colocada em uma categoria distinta por possuir características funcionais distintas das demais emoções positivas (SILVIA, 2001). No total, a frequência de emoções positivas foi de cento e uma ocorrências, a frequência da emoção interesse foi de quarenta e seis ocorrências, contra três ocorrências de emoções negativas.

Por se tratar de uma parcela praticamente irrelevante das emoções suscitadas, parece razoável pensarmos que a escolha da carreira de professor de Física não está ligada a eventos emocionais que envolvam emoções negativas. Ao que parece, a motivação para realizar o curso de licenciatura em Física contém um núcleo central voltado ao afeto positivo. Esse núcleo central comporta duas dimensões: emoção interesse e emoções positivas.

Quando um indivíduo resolve seguir a carreira de professor de Física, algumas questões devem, no mínimo mentalmente, ser respondidas: Por que Física? Por que o ensino de Física e não a pesquisa básica? O que me interessa na Física? As respostas a essas perguntas vinculam-se diretamente à emoção interesse. Diversos pesquisadores (HIDI, 1990; FREDRICKSON, 1998; KASHDAN et al., 2004; KRAPP, 2005; SILVIA, 2005, 2006) sugerem que interesse é a emoção positiva mais frequentemente experimentada, fornecendo grande parte da motivação para 0 aprendizado, o desenvolvimento de habilidades e competências e realizações criativas. Ele resulta de um aumento na estimulação neural, geralmente trazido por alguma mudança, conflito cognitivo ou novidade, mas também determina como as pessoas selecionam e persistem em processar preferencialmente certas informações do ambiente. Silvia (2001) argumenta que interesse leva as pessoas a participarem 
de novos, incertos ou complexos aspectos do mundo e, ao longo do tempo, cultivar conhecimento e habilidades. Isso nos leva a considerar que as sucessivas experiências da emoção interesse dos acadêmicos participantes deste estudo, em seus contatos com a Física ou ciência, contribuiu significativamente para escolha da carreira de professor.

O último raciocínio pode ser aplicado às emoções amor e alegria, embora devamos incluí-las na classe de emoções positivas, pois se referem mais ao valor afetivo atribuído pelos indivíduos a uma proposição, ação, objeto, conceito ou representação, do que a busca de informação no ambiente, através de sua exploração prática ou cognitiva. É um sentir-se em relação a algo. No caso dos acadêmicos consultados, traduzem as emoções, por exemplo, relativas a alguma experiência escolar rica, na qual tenham participado atentamente, discutido ou entendido profundamente um determinado conteúdo, registrando uma emoção positiva sobre a experiência na estrutura afeto-cognitiva. Thagard (2001) e Damásio (2005) defendem a hipótese de que o cérebro guarda experiências emocionais, aprendendo a tirar proveito delas visando a garantir sobrevivência e avaliar situações futuras. Sentimentos de medo e de tristeza, por exemplo, podem se constituir em formas importantes de analisar situações perigosas, assim como sentimentos positivos como alegria e felicidade são indícios de situações favoráveis à sobrevivência. Em resumo, a experiência de emoções positivas promove a interação com fontes familiares de emoções positivas. Ao que parece, a consciência da experiência dessas emoções positivas em algum momento da vida dos acadêmicos pesquisados apoiou a opção pela carreira de professor de Física.

Embora a emoção interesse e as demais emoções positivas sejam conceitualmente distintas pelas suas funções (Silvia, 2006), cada emoção pode gerar a outra, criando ciclos de interesse e satisfação. Silvia e Kashdan (2009) explicam que interesse motiva as pessoas a tentarem compreender coisas novas, conflitivas ou complexas. Se elas alcançam seu objetivo de compreender, sentimentos de alegria ou contentamento devem ser gerados. Da mesma forma, os sentimentos positivos tornam as pessoas mais dispostas a experimentar coisas novas e mais confiantes sobre sua capacidade de compreendê-las As pessoas em estados de ânimo positivos são, portanto, segundo esses autores, provavelmente mais suscetíveis de avaliar os eventos de forma a criar interesse. Essa estrutura sugere que, para o caso de os graduandos participantes desta pesquisa, a emoção interesse, experimentada com exposição a conteúdos ou situações relacionadas a Física, pode ter sido realimentada pelas emoções positivas geradas com tal exposição, e viceversa. 


\section{2. Experiências emocionais}

Na seção anterior, procuramos evidenciar qual motivação dos acadêmicos pesquisados para se tornarem professores de Física mantinha uma relação não aleatória com a dimensão afetiva. Mostramos a existência de um núcleo central composto por emoções positivas e emoção interesse. Agora, trataremos de analisar as experiências emocionais vividas pelos acadêmicos e como elas influenciaram suas escolhas. Entendemos experiência emocional como "sentimentos momentâneos que caracterizam experiência subjetiva" (Silvia, 2006, p. 142). A categorização realizada anteriormente nos leva a considerar dois tipos de experiências emocionais: experiência emocional positiva e experiência emocional do interesse.

\section{2. 1 Experiências emocionais positivas}

Nos relatos dos acadêmicos, foram encontradas experiências emocionais positivas ocorridas em diversas situações escolares ou relacionadas com a escola. Nelas, os graduandos explicitaram suas emoções em relação à compreensão de algum conteúdo de Física ou ao engajamento em atividades escolares. A partir dessas experiências, eles desenvolveram gradualmente a motivação para interagir com a Física e se tornarem professores. A participação em atividades escolares contribuiu para formação de atitudes positivas com relação à Física e, acima de tudo, como elemento de grande satisfação para os graduandos. A experiência emocional de Ester é um exemplo típico:

Sempre gostei das matérias de Física, Elétrica, Mecânica e Matemática. Como já havia feito o técnico em eletromecânica decidi cursar algo na área exata, e como não consegui definir qual das exatas gostava, optei por Física que englobava elétrica e Mecânica [...] Um assunto que eu adorava era a parte de manutenção elétrica, onde consertávamos e aprendíamos o funcionamento de motores elétricos.

Pela narrativa, podemos perceber afinidade com a área de exatas. Ester teve uma experiência bastante significativa com o Curso Técnico em Eletromecânica que fortaleceu a opção pelo Curso de Licenciatura em Física. Ela sinaliza, também, que as emoções positivas criadas na atividade didática com manutenção de motores, no Curso de Eletromecânica, foram fatores determinantes na decisão. Na exploração de equipamentos, ela foi descobrindo o gosto pela área da Física. Conforme salientam Liu e Treagust (2005), fatores educacionais, como o formato da atividade em classe, podem determinar o aumento do gosto por uma disciplina. 
Meirieu (2002) reconhece a necessidade de que no processo de escolarização se desloque "progressivamente a satisfação afetiva dos alunos para os objetos culturalmente valorizados" (p. 150). A motivação de alguns alunos para seguirem a carreira de professores de Física justifica-se por este tipo de satisfação, conforme atesta o extrato da narrativa de Lucas:

Quando entrei no colegial, tive meu primeiro contato direto com a Física. Foi praticamente amor à primeira vista. Apesar de ter sido sempre um aluno relapso e preguiçoso, sempre me dei bem nesta matéria, pois sempre gostei. Entender o porque das coisas me deixava muito empolgado.

Lucas argumenta que as dificuldades encontradas na vida escolar eram suplantadas devido ao gosto pela disciplina de Física. Ele faz uma referência explícita à função compreensão dos conteúdos na construção de emoções positivas com relação à Física. O termo "empolgado" denota claramente a emergência de sentimentos positivos com os objetos culturais da Física. Em seguida, Lucas é mais contundente ao esclarecer o impacto de suas experiências emocionais com a Física: "Acho que poderia dizer que escolhi fazer Licenciatura em Física porque eu gosto muito de Física e quero levar outras pessoas a gostarem também”. Comungando do mesmo estilo de pensamento de Lucas, José afirma:

Com o tempo descobri que o entendimento dos princípios básicos do funcionamento do universo me fascinava muito mais que a sua aplicação no projeto, construção e manutenção de dispositivos. Assim, o que realmente me motivou a fazer Física foi a busca de conhecimento. Não pensei se seria cientista ou professor, aliás, não pensei no que iria trabalhar ou como iria ganhar dinheiro depois da faculdade. Só sabia que a busca pelo conhecimento me fascinava e, por isso, resolvi fazer Física.

O gosto pelo saber, parece ter formado nestes graduados a base emocional suficiente para o desenvolvimento da intenção de investir em uma carreira ligada a Física. A experiência emocional de Maria apresenta similar teor:

Como gosto de entender como as coisas funcionam, vários fenômenos me intrigavam, portanto acho que tudo que está relacionado com a Tecnologia é fascinante [...] Quando frequentava o Ensino Médio, a Física me fascinava, pois as Ciências, de um modo geral, explicam de forma mais satisfatória o mundo à nossa volta, pois quando somos crianças todas as respostas que tivemos sobre como as coisas funcionam são: é assim que funciona e pronto! 
Maria deixa bem evidente sua satisfação com o saber. Para ela, o mundo se revestia de uma série de desafios intelectuais que a intrigavam constantemente, e a superação deles se tornava fonte de contentamento. $\mathrm{O}$ mundo tecnológico teve participação significativa na edificação dos seus sentimentos. Maria acredita que a Física consegue oferecer explicações mais satisfatórias. Neste caso, "satisfatória" comporta duas interpretações. Na primeira, mais cognitivista, pode-se entender como explicações mais plausíveis, que mostram como os fatos realmente decorrem da estrutura conceitual do modelo explicativo. Na segunda, mais afetiva, pode-se inferir a ocorrência de alguma realização emocional positiva com os saberes da Física.

Um outro tipo de experiência emocional positiva declarada pelos acadêmicos envolveu, ao mesmo tempo, a satisfação com a Física e com as situações informais de ensino, como a experiência de Daniel mostra:

Os meus amigos com dificuldades pediam a minha ajuda, e o mais impressionante é que, ao tentar explicar coerentemente, entendia ainda mais a matéria! E o pior, eles também entendiam! Comecei a me animar em arrumar formas de explicar a Física, e ai já era tarde demais, já havia me apaixonado por ela.

Daniel diz que, ao encontrar formas diferentes de explicar, aumentava gradativamente seu próprio entendimento do conteúdo. O sentido dos conceitos aflorava mais significativamente conforme as explicações eram repetidamente construídas. Por outro lado, sua motivação crescia no ato de procurar meios heurísticos de facilitar a explicação aos colegas. A paixão descrita por Daniel, no final da sua fala, nasceu da junção desses dois fatores, que apesar de natureza cognitiva, produziam como recompensa emoções positivas. São, de fato, sensações múltiplas, a de entendimento que veio com a significação e apropriação do conhecimento (tornou o conhecimento dele) e a consequente capacidade de compartilhar o conhecimento e também a sensação (ou emoção, ou sentimento) de entendimento com outros.

Felipe narra semelhante experiência, relativa ao prazer em ensinar os colegas, justificando sua inclinação para a licenciatura:

Durante todo Ensino Fundamental e Médio sempre tive uma aproximação maior com as matérias ditas exatas, com uma maior inclinação para Matemática e a Física. Como essas matérias sempre foram problemas de muitos alunos, muitas vezes eu estava ensinando as matérias para os colegas, e constantemente os colegas aprendiam melhor com minhas explicações. Sempre obtive prazer ao ensinar meus colegas. 
A característica comum das experiências de Daniel e Felipe é a satisfação em ensinar Física informalmente para os colegas, exercitando as suas habilidades e a sua criatividade. Essa experiência emocional catalisou o gosto deles pela disciplina, o qual, posteriormente, os inspirou a entrar no curso de Licenciatura em Física.

Finalmente, alguns acadêmicos relataram experiências emocionais positivas com o reconhecimento do fato que uma explicação foi alcançada. Tais experiências estão de acordo com a ideia de Gopnik (1998) de que os seres humanos procuram e são satisfeitos por explicações de objetos físicos, de padrões em eventos, de seres vivos, de agentes psicológicos e de grupos sociais. Gopnik sugere que "encontrar uma explicação para alguma coisa é acompanhado de uma satisfação que vai além do meramente cognitivo" (p. 102). Isso pode ser interpretado como a experiência subjetiva de um sentimento de entendimento: a satisfação intelectual e afetiva que provoca a aceitação de uma explicação (AUTOR, 2007). A experiência emocional de André é um exemplo típico:

Quando era aluno, ficava muito interessado quando percebia que aquilo que o professor falava fazia parte do meu dia a dia. Muitas vezes, eu via o fenômeno acontecer diante dos meus olhos, mas nunca havia parado para observá-lo de forma diferente. Depois das aulas de Física parecia que o mundo ao meu redor mudara. Foi assim com as aulas de momento de uma força [torque], dilatação térmica, fenômenos relacionados com a luz (refração, reflexão) e muitos outros.

No comentário de André, pode-se perceber que o conhecimento adquirido lhe permitiu ver em seu mundo coisas que antes não via. Não foi o reconhecimento do que é familiar, mas o estranhamento com aquilo que é familiar e os novos significados adquiridos, recriando o mundo, dando-lhe outra dimensão, que estabeleceram uma outra relação de aproximação com a Física. Ver as coisas para além das aparências é um desafio constante na Educação Científica, e André parece ter conseguido isso na sua vida escolar quando as entidades teóricas da Física lhe permitiam reinterpretar fenômenos familiares e gerar satisfação com seu êxito. Ao que parece, a descoberta de novos significados e do estranhamento torna o mundo das coisas uma fonte não apenas de questões, mas de possibilidades de realização da sensação agradável de significar e recriar.

Ana, em uma situação um pouco distinta, revela semelhantes padrões afetivos:

A decisão veio na 5 a série do Ensino Fundamental, quando dois episódios com a professora de ciências me fizeram escolher pela Física [...] A professora 
insistia em responder as minhas perguntas repetindo o que estava escrito no livro didático. Em uma aula sobre os planetas do sistema solar, ela repetia: "O sistema solar é composto por nove planetas". Na fase do por que, fiz a pergunta: "professora, como eles têm tanta certeza?" "o sistema solar é composto por nove planetas", foi a resposta. Ironicamente, na semana seguinte, o jornal publicou uma notícia sobre a possibilidade de um novo planeta... algumas aulas depois, "a lua só mostra uma face para Terra", a aluninha perguntadora: "mas, professora, se a lua gira, como pode?”. Mais uma vez, a resposta encontrada foi a repetição do livro. A dúvida persistiu até uma festa de aniversário onde, com dois balões, pude observar o resultado da combinação dos movimentos de rotação e translação da lua. Nesse dia, tive a certeza do meu destino.

Por que uma explicação aparentemente tão simples teve um efeito significativo na vida de Ana? Maturana (1997) considera que, quando se pede a alguém para explicar alguma coisa, espera-se uma explicação satisfatória. Então, o ouvinte, aquele que faz a pergunta, é aquele que decide o que será uma explicação. No caso de Ana, não havia satisfação com as respostas mecânicas da professora de Ciências. Ela não legitimava internamente as explicações oferecidas. Em outras palavras, não havia um entendimento associado com cargas afetivas positivas. Por outro lado, o momento da explicação com os balões teve um apelo afetivo tão intenso ao ponto de ela admitir ter consciência do seu destino na Licenciatura em Física. Para Ana, diferentemente de André, não foi a satisfação com uma explicação, ou um sentimento de entendimento, mas sim a falta dele, a fonte da insatisfação e o motor do interesse. Ela não buscava repetir a sensação que vem com um entendimento, mas sim buscar essa emoção, com a busca de explicações mais profundas.

A satisfação afetiva com as explicações também foi para a acadêmica Marta uma experiência emocional positiva:

Acho prazeroso qualquer dúvida esclarecida, seja alguma questão fundamental em minha mente que tenha resposta ou até mesmo um maldito exercício resolvido depois de horas de tentativas frustradas [...] Me estimulava bastante descobrir pequenos detalhes da natureza, como o porquê do céu ser azul e do crepúsculo ter tons em vermelho e laranja, ou porque os astronautas pareciam flutuar na lua e porque, na Terra, as pessoas caíam tão mais rápido [...] Para cada indivíduo, uma explicação tem certa importância em um aspecto determinado. O que parece um detalhe fútil pode ter imensa beleza visto por outro [...] a sensação é de que se é mais sábio em um pedacinho de conhecimento. 
As experiências emocionais citadas por Marta refletem os padrões afetivos sugeridos por Gopnik (1998) em sua descrição da fenomenologia das explicações. Gopnik afirma que nós, seres humanos, "não apenas conhecemos uma explicação quando temos uma, nós queremos explicações, e nós somos satisfeitos quando as conseguimos" (p. 109). Percebe-se, ainda, no complemento da narrativa de Marta, que o entendimento de uma explicação contém um fator subjetivo, que passa pela construção da plausibilidade. Marta parece ter consciência que é a aceitação, ou satisfação, de que quem recebe a explicação que constitui a relevância da explicação; portanto, não basta recebê-la de alguém (um professor, por exemplo), mas sim se apropriar da explicação, torná-la de si mesma.

A narrativa de Paulo sintetiza o tipo de experiência emocional positiva criado por explicações:

Tive satisfação de entender a parte de movimento relativo, como por exemplo: Por que os pingos de chuva parecem mudar de direção quando estamos dentro de um carro e começamos a entrar em movimento.

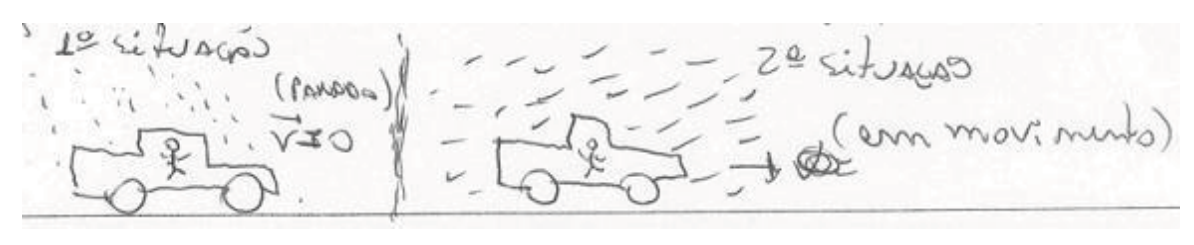

Fig. 2 - Representação de Paulo.

Nos últimos casos acima, fica claro que a satisfação com o entendimento, ligada às explicações, está relacionada à apropriação dos saberes da Física, pois, quando os estudantes compreendiam e até ensinavam, isto é, explicavam, tinham um conhecimento significativo, fruto de um processo de elaboração interna e própria, orientado pelos seus processos de busca e construção de explicações. Ademais, depreende-se que a valoração ou o significado dado ao conhecimento pode ser múltiplo. Por exemplo, um conhecimento escolar compartilhado através do ato de ensinar aos colegas pode ser diferente do prazer em explicar fenômenos naturais associados ou não ao nosso cotidiano. 


\section{2. 1. Experiências emocionais do interesse}

A busca de dar sentido ao que é experienciado, o flerte com o desconhecido, denotam uma das capacidades humanas mais sensacionais e necessárias (FREDRICKSON, 1998). Uma das grandes motivações dos acadêmicos pesquisados para ingressarem no curso de Licenciatura em Física se associou com a busca de informação, do entendimento do funcionamento do mundo natural ou artificial. Para alguns acadêmicos, desde cedo, o mundo se configurava como um ambiente desafiador que instigava sua curiosidade, fazendo com que eles buscassem mais conhecimento. A experiência emocional do interesse de Daniel é um exemplo característico:

Quando eu era pequeno queria conhecer coisas novas sobre tudo. E tinha várias dúvidas: como o céu é azul de dia e, a noite, é preto? Não rosa? Minha mãe não pode dar essas respostas, mas eu lia muito umas antigas enciclopédias dela [...] e de lá aprendia muitas coisas, pois a linguagem era bem simples.

Similarmente, Lucas relata:

Para entender o que me levou a fazer um curso superior de Física, primeiramente, preciso relembrar minha infância. Sempre fui uma criança muito curiosa. Sempre quis saber o porquê das coisas. Perdi a conta de quantos rádios, controles e aparelhos eletrodomésticos estraguei abrindo para tentar entender o seu funcionamento. O modo como as coisas funcionavam apenas pelo fato de ligar na tomada sempre me chamou a atenção.

As explorações feitas quando crianças ou adolescente levaram Daniel e Lucas a cultivar o interesse pela Física. Daniel, por exemplo, admitiu sua vontade de conhecer coisas novas, ligadas ao mundo natural. O desequilíbrio provocado pela ideia de que o céu pudesse ter outra coloração diferente daquela frequentemente observada o conduzia a continuar explorando, na tentativa de dar sentido ao objeto de desequilíbrio. A procura por outras fontes de informação frente às respostas evasivas da sua mãe manteve acesa a chama do desejo de conhecer. A leitura espontânea da enciclopédia fez com que ele encontrasse alguma acomodação aos anseios da mente em entender as situações provocadoras propiciadas pelo ambiente. A busca da intimidade com a natureza, de familiarizar-se com aquilo que embora cotidiano, fomentou e dirigiu seu caminho até o curso de licenciatura em física, local em que pretendia encontrar novas experiências emocionais do interesse. Lucas, por sua vez, divertia-se manipulando os aparelhos eletrônicos em casa. Sua exploração, tanto mental quanto física, sobre esses objetos, decorrente do 
interesse e acompanhada do sentido cognitivo construído naquele momento, instigou-o a perseguir uma carreira que lhe despertasse novos sentimentos de interesse e satisfação.

A experiência da emoção do interesse também se intensifica com o compartilhamento das sensações positivas vivenciadas. Encontrar no outro alguma sintonia com o nosso pensar, por vezes, estimula a crescente busca do conhecer. Nesses casos, nem sempre há ligação direta entre o observador e o objeto de cobiça intelectual. A descoberta acontece por intermédio do contato com jornais, revistas e discussões, o elemento final continua sendo o mesmo, porém via outro tipo de intermediação semiótica, conforme Levi descreve:

Tenho um amigo que estudou comigo, por várias séries [...] Com ele eu conversava bastante sobre diversos assuntos, mas tínhamos especial interesse e discutíamos como as coisas funcionam. Discutíamos sempre estimulados por alguma leitura de algum artigo técnico ou científico ou por vezes líamos em jornais, revistas ou livros. Não éramos sistemáticos em tais leituras, mas quando algo do tipo científico, mecânico ou eletrônico caía em nossas mãos nós líamos e discutíamos.

Levi alimentou seu interesse recorrendo a revistas de divulgação científica e compartilhando essa atividade com seu amigo. Embora a maior parte dos professores não use materiais de divulgação científica em suas aulas, são de fácil acesso e bastante difundidos, e, muitas vezes, transitam nas salas de aula mesmo antes do contato formal com disciplinas científicas. Os estudantes querem saber sobre temas atuais, como clonagem, a idade do universo, lasers, entre outros. Entretanto, o currículo, carregado de conteúdos teóricos, não deixa espaço para que assuntos que interessem aos estudantes sejam trazidos para a discussão. O relato de Levi, perceptivelmente, ilustra a ação individual direcionada ao objetivo de encontrar situações cuja emoção do interesse fosse experimentada. O cultivo dessa prática, acompanhado do prazer gerado, incrementou o contexto afetivo da escolha da profissão.

Criatividade, um outro atributo, descrito na narração de Saul, realça a importância da experiência emocional do interesse no processo embrionário de ingressar na Licenciatura em Física:

$O$ interesse pelo assunto vem de longe, de criança. A falta de recursos para aquisição de brinquedos, ferramentas entre outros objetos prontos, obrigavame a usar a criatividade para produzi-los com outros materiais disponiveis. Estou certo de que a facilidade de entender os primeiros conceitos de mecânica veio desse fato. Em seguida, devido ao interesse de saber como as coisas funcionam, 
como se comportam diante de determinada situação, realizava experiências por conta própria.

Resolver problemas por conta própria ofereceu para Saul à oportunidade do desenvolvimento de um ambiente propício à exploração livre. Mais do que êxito em encontrar a resposta correta, entrou em jogo a ciranda do criar, tentar soluções alternativas, por meio de caminhos construídos durante o pensar. A resposta dada por Saul às condições do ambiente ampliou sua identificação com a área da Física, fazendo sua mente e suas emoções gozarem o processo criativo. Consultando suas reminiscências, Saul trouxe à tona um episódio emocional marcante, no qual tinha necessidade de encontrar alternativas viáveis, mais tarde convertidas em processo mais complexo de descoberta em situações controladas por ele. Russ (1993) afirma que as conexões entre processos cognitivos e afetivos são importantes para os processos criativos.

Dar sentido às relações matemáticas por intermédio da Física se constitui igualmente em fomento ao interesse pela disciplina, como declara Gabriel:

Comecei a estudar para o vestibular visando ao curso de Física, para mais tarde me especializar em mecatrônica, já que o meu sonho era trabalhar com robótica, pois sempre tive muito interesse em como essas máquinas funcionam, pois é como se desse vida a um pedaço de metal. Fui à escola pública onde estudava e encontrei um livro de Física. O primeiro assunto que comecei a estudar foi estática, e o que mais me chamou a atenção foi saber que a Matemática servia para explicar aqueles fenômenos e me interessei de verdade por Física, porque ela dava um sentido (que eu ainda não havia encontrado) à Matemática que nós aprendíamos.

Na primeira parte do extrato, novamente aparece a curiosidade por artefatos, fortalecida dramaticamente pela argumentação que as máquinas parecem ter vida. Na parte final, Gabriel confessa que o sentido dado à matemática com os conteúdos de estática fez despertar seu interesse pela Física. Ao que parece, até então, Francisco convivia com raciocínios desconexos da realidade resolvendo exercícios de matemática, quando percebeu que a Física podia interpretar a realidade e oferecer significado aos cálculos abstratos.

Pedro, outro acadêmico, relata experiência emocional semelhante à de Francisco, na qual interesse e busca de sentido, integraram sua motivação para cursar a Licenciatura em Física:

Cada ser humano é inato às questões que são pertinentes ao funcionamento de tudo que os cercam [...] A minha escolha refloresceu de saber como todo 
este mundo funciona, não prendi a atenção em como funcionavam objetos pequenos que permeavam a minha infância, mas tentava compreender como esse 'objeto' [a Terra] tão imenso que está presente em todos os dias, em todas as horas, a cada minuto e com o passar de cada segundo permeia a minha vida [...] Com o passar dos anos, professores falavam para mim que eu tinha grande facilidade de lidar com números; por essa e outras afirmações, pensei em investir no ramo da matemática. No entanto, quando pensava nesses números e não conseguia transpôlos para sanar as minhas indagações sobre o mundo, senti-me um pouco decepcionado. Até que comecei a estudar no Ensino Médio, e me deparei com uma nova matéria: a Física [...] a Física conseguia sanar meus questionamentos de mundo, de uma forma simples, correlacionada com números e, principalmente, muito bonita.

A busca de entendimento do mundo, comum na infância de Pedro, pode ser revivida com a expectativa gerada pelo ingresso no curso. Está claro que Pedro tinha uma inclinação pela área de exatas, entretanto, a matemática não lhe era suficiente, porque não gerava explicações e no seu entendimento, apenas lidava com lógica. Ao lado do interesse por explicações, podemos identificar o descontentamento com a matemática pura. Ueno et al. (2003) interpretam que, quando um aluno tem a satisfação de resolver problemas de Matemática, e encontra na Física a possibilidade de obter respostas às suas inquietações, à sua curiosidade natural, ele consegue unificar essas duas satisfações, aumentando o grau de satisfação em relação ao conhecimento, porque se adicionam o prazer de resolver problemas e o de entender.

Por fim, algumas experiências emocionais relevantes na decisão de se tornar professor de Física acontecem na escola e são mediadas pela relação professoraluno. As situações escolares contribuem de diferentes formas para a formação de um perfil voltado ao ensino. O professor, até mesmo por ser o foco das atividades de ensino tradicionais, acaba se tornado uma referência para o aluno. Entretanto, essa referência nem sempre é positiva. É comum ouvirmos os alunos reclamarem dos maus professores, pouco compromissados com a disciplina ou com o desempenho dos alunos. Professores desse tipo costumam ficar presos à inércia da repetição dos métodos tradicionais (Arruda, 2001). Outros, porém, exercem a profissão com afinco e paixão, contagiando os alunos e servindo de instrumento de incentivo e espelho para os planos futuros dos alunos, despertando neles o interesse e gosto pela Física. Judite, por exemplo, expressa esse padrão afetivo:

Eu sempre tive facilidade com Matemática no Ensino Fundamental e, ao iniciar o Ensino Médio, meu professor de Física percebeu esta facilidade e foi 
despertando meu interesse pela Física. Ele me levou ao IF-USP e sempre me incentivou muito.

Judite indica que o incentivo do professor, aliado à sua facilidade com a Matemática no Ensino Fundamental, levou-a ao curso de licenciatura em Física. Nesse trecho, ela reconhece na percepção do professor de sua aptidão com as disciplinas exatas, bem como a iniciativa de levá-la ao Instituto de Física da USP, referências positivas no crescimento do seu interesse pela física. $\mathrm{O}$ professor criou um ambiente propício à experiência da emoção do interesse.

Para outros acadêmicos, os professores também serviram de referência devido às suas ações em sala de aula. Timóteo, por exemplo, passou a apreciar a Física somente após as aulas ministradas no segundo ano do Ensino Médio, conforme relata:

Meu interesse pela Física começou no segundo ano do Ensino Médio, graças a um ótimo professor com quem tive aula. Antes de tal experiência, não conseguia apreciar a Física e muito menos tirar boas notas.

O professor mostrou para Timóteo uma nova maneira de ver o mundo, por meio das explicações dadas pelas teorias físicas. Isso criou nele experiências emocionais positivas e do interesse, melhorando seu desempenho naquele momento, e contribuiu para a escolha da profissão de professor de Física. Esse aspecto importante da participação docente na escolha dos graduandos é corroborado por André.

Acredito que a aptidão, a didática dos professores e o fato do conhecimento de Física ser 'palpável' e interessante a mim foram elementos cruciais na minha escolha, a falta de qualquer um deles teria me levado à desistência da carreira. Sem bons professores eu não teria interesse algum, sem aptidão não aprenderia nada e, sem esse lado real da Física, pensaria que esse conhecimento fosse inacessivel para não gênios.

Fruto das ações do professor, André cita a percepção concreta dos saberes físicos como fator crucial na sua escolha. A asserção o lado real da Física oferece a dimensão de proximidade com o saber físico vivido, certamente pelas contextualizações realizadas pelo professor e responsáveis por trazer a Física para os centros de interesse de André. Isso fica claro no argumento: "quando era aluno, ficava muito interessado quando percebia que aquilo que o professor falava fazia parte do meu dia a dia”. A condução da relação didática foi um elemento essencial na construção de situações de experiência da emoção do interesse em André. 


\section{Discussão}

Nossos resultados evidenciam que as experiências emocionais dos acadêmicos pesquisados formaram parte importante de suas motivações para se tornarem professores de Física. Estes acadêmicos construíram ligações duradouras com a Física, pois, conforme seus relatos, atitudes positivas sobre a Física se tornaram traços característicos de suas personalidades. Todavia, experiências emocionais são, por natureza, passageiras e, muitas vezes, desconexas. Por exemplo, um aluno pode experimentar a emoção do interesse por artefatos quando a professora organiza uma visita a um museu, mas as subsequentes aulas dedicadas ao escrutínio minucioso, em termos de leis físicas, do funcionamento de uma máquina em particular pode ser frustrante para ele. Isso quer dizer que experiência emocional não é o único requisito para criação de uma relação favorável estável com um objeto. Então, falta-nos um mecanismo capaz de explicar como experiências emocionais positivas e do interesse momentâneas influenciaram o desenvolvimento de interes$\operatorname{ses}^{l}$ duradouros nos indivíduos pesquisados.

Recentemente, Silvia (2006) elaborou argumentos bastante convincentes a respeito do desenvolvimento de interesses individuais baseados em dois elementos: (i) experiência emocional e (ii) conhecimento emocional. Em linhas gerais, Silvia considera que a criação de interesses duradouros envolve, além da experiência emocional, o desenvolvimento de conhecimento emocional. Segundo Silvia, o conhecimento emocional habilita as pessoas a fazerem atribuições para as causas de suas emoções e formar expectativas considerando os prováveis efeitos emocionais de suas ações. Sobre o conhecimento emocional, Silvia se apoia fortemente na teoria da atribuição e sua defesa da capacidade humana de organizar os eventos em relações de causa-efeito.

Para o entendimento do modelo de Silvia, é importante compreender qual o significado do termo atribuição. Uma atribuição é uma explicação causal para um evento ou comportamento (WEINER, 1985). Por exemplo, se um professor observa um colega utilizando uma metodologia incorreta como um aluno, ele provavelmente tentará encontrar uma explicação atribuicional para este comportamento. O professor pode concluir que seu colega tem formação não adequada para o magistério, significando que o observador está atribuindo o comportamento à falta de habilidade. Pessoas também geram atribuições sobre os seus próprios comportamentos e desempenho. Por exemplo, um professor pode atribuir o sucesso de um

\footnotetext{
${ }^{1}$ Utilizaremos interesse para nos referirmos à experiência emocional momentânea do interesse e interesses para interesse individual duradouro.
} 
aluno a suas competências como educador, ou ao comprometimento do aluno, dentre outras atribuições possíveis. Em síntese, as pessoas procuram explicar a causa das coisas, os "porquês", isto é, a motivação das condutas próprias e dos outros, implicando que suas condutas são afetadas pelas atribuições de causalidade que elas realizam (WEINER, 2000).

No caso das emoções, tudo se passa conforme o mesmo mecanismo, pois existe uma reação geral positiva ou negativa, baseada no sucesso ou fracasso percebido sobre o resultado de um acontecimento, e uma inclusão causal. Por exemplo, uma reação afetiva positiva com relação à Física, tal como satisfação com a disciplina, pode ser atribuída ao desempenho do professor em certa situação didática. Assim, atribuições permitem às pessoas interpretarem as causas dos eventos para que possam experimentá-los novamente. Quando os resultados são desagradáveis, atribuições permitem identificar e evitar os comportamentos e outros fatores que causam sua ocorrência (WEINER, 1986).

Silvia (2006) parte do princípio que seres humanos podem se tornar conscientes do fato que estão experimentando uma emoção, podem pensar sobre está experiência emocional, podem pensar sobre seus pensamentos sobre suas emoções, para desenvolver o modelo atribuição-expectativa do interesse. O desenvolvimento de interesses, de acordo com modelo atribuição-expectativa de Silvia, envolve o conhecimento emocional sobre a experiência emocional do interesse. Cognições sobre a experiência emocional do interesse, como atribuições causais, informam para as pessoas porque elas se sentiram interessadas e $o$ que as fez se sentirem interessadas, pensamentos metacognitivos sobre as emoções, como expectativas e planejamento baseado nas atribuições, informam como elas podem criar sentimentos de interesse no futuro.

Consideremos, por exemplo, uma pessoa que foi a um parque de ciências, e atribuiu sentimentos de interesse à atividade. Ela é capaz de indicar a fonte de interesse e criar expectativas sobre repetir essa sensação em novas visitas, sabe também o meio, visitar o parque, para alcançar o fim, a experiência do interesse. Esse processo cognitivo e metacognitivo repetido em diversas experiências similares formam a ponte entre interesse momentâneo e o desenvolvimento do interesse individual. Aliado a isso, Silvia argumenta que experiências emocionais positivas são relevantes para o desenvolvimento de interesses, pois "engajam as pessoas com atividades simples e familiares" (p. 144), enquanto emoções negativas atuam como inibidores do processo. Se uma pessoa experimenta emoções negativas durante uma atividade na qual o interesse ainda é incipiente, pode atribuir essas emoções à atividade e suas expectativas sobre as experiências emocionais em relação à atividade podem gerar condutas de evitação, neste caso o interesse individual não 
prosperará. $\mathrm{O}$ interesse em parques de ciência, por exemplo, pode decair quando a pessoa percebe as complicações técnicas e teóricas para explicar os eventos mostrados no parque e o tempo que deverá despender para sua compreensão. Em vez de esperar sentimentos de interesse e alegria, a pessoa irá esperar sentimentos de frustração e, para evitar esses sentimentos, irá evitar a atividade, inibindo o possível desenvolvimento de um interesse duradouro.

Mas como o modelo de Silvia explica o caso dos acadêmicos investigados? Temos a impressão de que as experiências emocionais momentâneas dos acadêmicos, nas diversas situações por eles elencadas, criaram uma estrutura de conhecimento emocional a respeito da ciência, e da Física em particular, nas suas diversas dimensões (explicação dos fenômenos, formalismo, docência, entre outros). Assim, ao que parece, o interesse duradouro deles, materializado na escolha da carreira de professor de Física, decorreu do conhecimento que certos eventos criaram a emoção do interesse e emoções positivas no passado, da expectativa que iriam criar a emoção do interesse e emoções positivas no futuro, e do conhecimento de como trazer à tona essas emoções do interesse e emoções positivas.

\section{Conclusão}

A análise precedente mostrou que as razões apontadas pelos acadêmicos investigados para escolha da carreira de professor de Física são fortemente marcadas por cargas afetivas, que não devem ser consideradas como um ruído, pois representam a construção de vínculos duradouros. Os resultados empíricos apresentados indicam a existência de diversas situações capazes de gerar experiências emocionais positivas nos indivíduos, algumas delas controláveis, como aquelas vindas do ensino formal; e outras não, como aquelas oriundas do contato informal com os saberes científicos e objetos tecnológicos. Isso nos leva a considerar que, no ensino formal, os educadores devem tomar como um objetivo de ensino despertar emoções positivas e do interesse em seus alunos. Acreditamos que, assim, seria dada grande contribuição para solução dos problemas da falta de interesse pelas disciplinas científicas e baixa procura por cursos da área científica, em particular da Licenciatura em Física. Mas como despertar essas emoções?

Pietrocola (2001) afirma que se os alunos percebessem o conhecimento científico ensinado na escola como meio eficaz de entender a realidade haveria mais garantia de vida pós-escolar ao mesmo, permitindo a construção de relações afetivas permanentes com o saber, porque os conhecimentos que usualmente nos acompanham por toda a vida são aqueles úteis ou que geram algum tipo de prazer. Então, uma das condições necessárias para construção da satisfação com o saber é 
que eles sejam significativos (BZUNECK, 2010). A dependência da redução do interesse com um tema científico, devido à falta de relevância pessoal imediata, é consistente com a análise de Osborne e Collins (2001) de que estudantes são mais interessados em aspectos da ciência que eles percebem como sendo relevantes para suas vidas, e menos interessados em tópicos que eles percebem como sendo de pouca relevância pessoal. Assim, uma primeira condição para que o aluno experimente emoções positivas com o saberes (e atividades escolares) é que ele o valorize, veja importância ou significado pessoal neles.

Outra variável importante parece ser a qualidade do ensino que os estudantes experimentaram e a personalidade dos professores que tiveram. Nos relatos dos acadêmicos participantes desse estudo, encontramos várias referências aos professores que eles tiveram e aos recursos didáticos que utilizavam para melhorar a aprendizagem ou motivação dos alunos. Evidências de que a qualidade de ensino da ciência é significante na formação de atitudes positivas sobre a ciência são encontradas no trabalho de Woolnough (1994). Woolnough encontrou evidências de que a qualidade do ensino, na opinião de estudantes de ciências, é determinada pela qualificação e pelo entusiasmo do grupo de professores. $\mathrm{O}$ bom ensino foi caracterizado por professores sendo entusiásticos sobre suas disciplinas, inserindo-as em contextos da vida dos alunos e desenvolvendo aulas estimulantes e bem preparadas. Similarmente, Raved e Assaraf (2011) mostraram que os fatores mais importantes capazes de influenciar a atitude dos estudantes do Ensino Médio em sala de aula são a relação interpessoal entre aluno e professor, a relevância e autenticidade dos tópicos sendo estudados e a diversificação dos métodos de ensino. Quadros et al. (2005) investigaram fatores que influenciam na formação da identidade docente e na opção pela carreira de estudantes do curso de Licenciatura em Química da Universidade Federal de Minas Gerais (UFMG). Quadros et al. encontraram vários fatores envolvidos nessa escolha, dentre eles, características marcantes de professores que esses estudantes tiveram. Foram citados aspectos pedagógicos e afetivos, tais como: a metodologia usada pelos professores, a amizade, o companheirismo, o bom humor, o diálogo constante, a atenção, entre outros. Eles argumentam que o professor acaba sendo, em alguns casos, o grande motivador da escolha da carreira pelos alunos.

Assim, nossos resultados apontam que o professor e seu estilo de ensino são fundamentais para o desenvolvimento de atitudes positivas sobre a ciência e tem influência direta nas escolhas profissionais dos estudantes. Isso está de acordo com a opinião de Osborne et al. (2003) que "a mais importante mudança que pode ser feita para melhorar a qualidade da educação científica poderia ser o recrutamento e retenção de hábeis e entusiásticos professores de ciências” (p. 1069). A 
qualidade do ensino que os acadêmicos desse estudo tiveram foi decisiva em suas escolhas. Portanto, somos levados a considerar que uma das soluções para escassez de professores de Física no Ensino Médio e a baixa motivação na disciplina está na melhoria da instrução oferecida neste nível, tal como assinalaram recentemente Brock e Rocha Filho (2011). Todavia, esta afirmação requer mais investigação empírica.

Por outro lado, não somos ingênuos de atribuir somente à dimensão afetiva a escolha da profissão. Nosso relato optou em evidenciar essa dimensão, entretanto, outros fatores foram citados pelos graduandos. A necessidade de emprego, a adequação do horário, questões salariais, dentre outros, surgiram nas narrativas e estão de acordo com a análise de Wang (2004). Entretanto, grande maioria das argumentações foi de ordem afetiva, uma boa evidência de que postular a existência de um núcleo afetivo voltado às emoções positivas é razoavelmente plausível. Poder-se-ia contra-atacar dizendo que são alunos de cursos da área de ciências, é natural que gostem de ciências, contudo não é natural a construção do gostar de ciências, por isso, focalizamos exatamente os episódios e as representações fundamentais para a construção desses vínculos afetivos.

\section{Referências Bibliográficas}

ALSOP, S. (Ed.). Beyond cartesian dualism: encountering affect in the teaching and learning of science. Dordrecht: Kluwer Academic Publishers, 2005. 199 p.

ALSOP, S.; WATTS, M. Sources from a Somerset Village: a model for informal learning about radiation and radioactivity. Science Education, New York, v. 81, n. 6, p. 633-650, nov. 1997.

ALSOP, S.; WATTS, M. Facts and feelings: exploring the affective domain in the learning of physics. Physics Education, Philadelphia, v. 35, n. 2, p. 132-138, mar. 2000 .

ARRUDA, S. M. Entre a inércia e a busca: reflexões sobre a formação em serviço de professores de Física do ensino médio. 2001. Tese (Doutorado em Educação) - Faculdade de Educação, USP, São Paulo.

BARAM-TSABARI, A.; YARDEN, A. Characterizing children's spontaneous interests in science and technology. International Journal of Science Education, London, v. 27, n. 7, p. 803-826, jun. 2005. 
BORGES, O. Formação inicial de professores de Física: Formar mais! Formar melhor! Revista Brasileira de Ensino de Física, São Paulo, v. 28, n. 2, p. 135142, jun. 2006.

BROCK, C.; J. ROCHA FILHO, J. B. Algumas origens da rejeição pela carreira profissional no magistério em Física. Caderno Brasileiro de Ensino de Física, Florianópolis, v. 28, n. 2, p. 356-372, ago. 2011.

BUCCHERI, G; GURBER, N. A.; BRUHWILER, C. The impact of gender on interest in science topics and the choice of scientific and technical vocations. International Journal of Science Education, London, v. 33, n. 1, p. 159-178, jan. 2011.

BZUNECK, J. A. Como motivar os alunos: sugestões práticas. In: BORUCHOVITCH, E.; BZUNECK, J. A.; GUIMARÃES, S. E. R. (Orgs.). Motivação para aprender: aplicações no contexto educativo. (p. 13-42). Petrópolis: Editora Vozes, 2010.

BYBEE, R.; McCRAE, B. Scientific literacy and student attitudes: perspectives from PISA 2006 science. International Journal of Science Education, London, v. 33, n. 1, p. 7-26, jan. 2011.

CAMPOS, P. H. F.; ROUQUETE, M-L. Abordagem estrutural e componente afetivo das representações sociais. Psicologia: Reflexão e Crítica, Porto Alegre, v. 16, n. 3, p. 435-445, 2003.

CUSTÓDIO, J. F. Explicando explicações na educação científica: domínio cognitivo, status afetivo e sentimento de entendimento. 2007. Tese (Doutorado) - Florianópolis, UFSC.

DAMÁSIO, A. O erro de Descartes: emoção, razão e o cérebro humano. São Paulo: Companhia das Letras, 2005.

DAWSON, C. Upper primary boys' and girls' interests in science: have they changed since 1980? International Journal of Science Education, London, v. 22, n. 6, p. 557-570, may 2005.

EKMAN, P. Expression and the nature of emotions. In: SCHERER, K. S.; EKMAN (Eds.). Approaches to emotion. (p. 319-343). Hillsdale, NJ: Erlbaum, 1984. 
EPSTEIN, S. Controversial issues in emotion theory. In: SHAVER, P. (Ed.). Review of personality and social psychology. (p. 64-88). Beverly Hills, CA: Sage, 1984.

FREDRICKSON, A. L. What Good Are Positive Emotions? Review of General Psychology, Washington, v. 2, n. 3, p. 300-319, set. 1998.

GOBARA, S. T.; GARCIA, J. R. B. As licenciaturas em Física das universidades brasileiras: um diagnóstico da formação inicial de professores de física. Revista Brasileira de Ensino de Física, São Paulo, v. 29, n. 4, p. 519-525, 2007.

GÓMEZ-CHACÓN, I. M. Matemática emocional: os afetos na aprendizagem matemática. Porto Alegre: Artmed, 2003a. 255 p.

GÓMEZ-CHACÓN, I. M. La tarea intelectual em matemáticas: afecto, meta-afeto y los sistemas de creencias. Boletín de la Asociación Matemática Venezolana, Caracas, v. X, n. 2, p. 225-247, 2003 b.

GÓMEZ-CHACÓN, I. M.; OP'T EYNDE, P.; de CORTE, E. Creencias de los estudiantes de matemáticas. La influencia del contexto de clase. Enseñanza de las Ciencias, Barcelona, v. 24, n. 3, p. 309-324, nov. 2006.

GOPNIK, A. Explanation as orgasm. Minds and machines, v. 8, p. 101-118, 1998.

IZARD, C. Human emotions. New York: Plenum Press, 1977.

KASHDAN, T. B.; ROSE, P.; FINCHAM, F. D. Curiosity and exploration: Facilitating positive subjective experiences and personal growth opportunities. Journal of personality assessment, Falls Church, v. 82, n. 3, p. 291-305, 2004.

KAHLE, J. B; LAKES, M. K. The mith of equality in science classroom. Journal of research in science teaching, v. 20, p 131-140, 1983.

KJAERNSLI, M.; LIE, S. Students' Preference for Science Careers: International comparisons based on PISA 2006. International Journal of Science Education, London, v. 33, n. 1, p. 121-144, jan. 2011.

KRAPP, A. Basic needs and the development of interest and intrinsic motivational orientations. Learning and Instruction, v. 15, n. 5, p. 381-395, oct. 2005. 
KRAPP, A.; PRENZEL, M. Research on interest in science: theories, methods, and findings. International Journal of Science Education, London, v. 33, n. 1, p. 27 50, jan. 2011 .

LIU, C.-J.; TREAGUST, D. F. An instrument for assessing students' mental state and the learning environment in science education. International Journal of Science and Mathematics Education, v. 3, p. 625-637, 2005.

MANO, H.; OLIVER, R. L. Assessing the dimensionality and structure of the consumption experience: evaluation, feeling and satisfaction. Journal of Consumer Research, v. 20, p. 451-466, 1993.

MATURANA, H. A Ontologia da Realidade. Belo Horizonte: Ed. UFMG, 1997.

MEIRIEU, P. A pedagogia entre o dizer e o fazer: a coragem de começar. Porto Alegre: Artmed, 2002. 302 p.

MORTIMER, E. Conceptual change or conceptual profile change. Science \& Education, New York, v. 4, n. 3, p. 267-285, jul. 1995.

NIESWANDT, M. Attitudes toward science: a review of the field. In: ALSOP, S. (Ed.). Beyond Cartesian Dualism: Encountering Affect in the Teaching and Learning of Science. (p. 41-52). Dordrecht: Kluwer Academic Publishers, 2005.

OON P.-T.; SUBRAMANIAM, R. On the Declining Interest in Physics among Students - From the perspective of teachers. International Journal of Science Education, London, v. 33, n. 5, p. 727-746, march 2011.

OSBORNE, J.; COLLINS, S. Pupils' view of the role and value of the science curriculum: a focus-group study. International Journal of Science Education, London, v. 23, n. 5, p. 441-467, may 2001.

OSBORNE, J.; SIMON, S.; COLLINS, S. Attitudes towards science: a review of the literature and its implications. International Journal of Science Education, London, v. 25, n. 9, p. 1049-1079, Set. 2003.

PARK, H., KHAN, S.; PETRINA, S. ICT in Science Education: A quasiexperimental study of achievement, attitudes toward science, and career aspirations of Korean middle school students. International Journal of Science Education, London, v. 31, n. 8, p. 993-1012, jul. 2009. 
PIETROCOLA, M. Construção e realidade: o papel do conhecimento físico no entendimento do mundo. In: , M. (Org.). Ensino de Física: conteúdo, metodologia e epistemologia numa abordagem integradora. (p. 9-32). Florianópolis: Editora da Universidade Federal de Santa Catarina, 2001.

PINTRICH, P. R.; MARX, R. W.; BOYLE, R. A. Beyond cold conceptual change: the role of motivational beliefs and classroom contextual factors in the process of conceptual change. Review of educational research, Pittsburgh, v. 63, n. 2, p. 167-200, summer 1993.

QUADROS, A. L. de et al. Os professores que tivemos e a formação da nossa identidade como docentes: um encontro com nossa memória. Revista Ensaio, Belo Horizonte, v. 7, n. 1, p. 9-18, 2005.

RAVED, L.; ASSARAF, O. B. Z. Attitudes towards Science Learning among 10th-Grade Students: a qualitative look. International Journal of Science Education, London, v. 33, n. 9, p. 1219-1243, jun. 2011.

REISS, M. J. The importance of affect in science education. In: ALSOP, S. (Ed.). Beyond cartesian dualism: encountering affect in the teaching and learning of science. (p. 17-25). Dordrecht: Kluwer Academic Publishers, 2005.

RUIZ, A. I.; RAMOS, M. N.; HINGEL, M. Escassez de professores no ensino médio: propostas estruturais e emergenciais. Ministério da Educação. Conselho Nacional de Educação. Brasília: CNE/CEB, 2007.

RUSS, S. W. Affect and creativity: the role of affect and play in the creative process. Hillsdale, NJ: Laurence Erlbaum, 1993.

RUSSEL, J. A. et al. (Eds.). Everyday Conceptions of Emotion: An Introduction to the psychology, anthropology and linguistics of emotion. Dordrecht: Kluwer Academic Publishers, 1995. 608 p.

SHAVER, P.; SCHWRATZ, J.; KIRSON, D.; O'CONNOR, C. Emotion knowledge: further exploration of prototype approach. Journal of personality and social psychology, v. 52, n. 6, p. 1061-1086, 1987.

SILVIA, P. J. Interest and interests: The psychology of constructive capriciousness. Review of General Psychology, Washington, v. 5, n. 3, p. 270-290, set. 2001. 
SILVIA, P. J. What is interesting? Exploring the appraisal structure of interest. Emotion, v. 5, n. 1, p. 89-102, mar. 2005.

SILVIA, P. J. Exploring the psychology of interest. New York: Oxford University Press, 2006. 263p.

SILVIA, P. J.; KASHDAN, T. B. Interesting things and curious people: exploration and engagement as transient states and enduring strengths. Social and Personality Psychology Compass, Boston, v. 3, n. 5, p. 785-797, set. 2009.

SUNDBERG, R. A.; DINI, M. L.; LI, E. Decreasing course content improves students comprehension of science and attitudes toward science in freshman biology. Journal of Research in Science Teaching, New York, v. 31, n. 7, p. 679-693, set. 1994.

THAGARD, P. Coherence, emotion, and practical inference. In: MILGRAM, E. (Ed.). Varieties of practical inference. (p. 355-371). Cambridge, MA: MIT Press, 2001 .

TYSON, L. M. et al. A multidimensional framework for interpreting conceptual change events in the classroom. Science Education, New York, v. 81, n. 4, p. 387 404, jul. 1997.

UENO, M. H.; ARRUDA, S. M.; VILLANI, A. Uma reflexão sobre o gostar de Física segundo uma abordagem psicanalítica. In: ENCONTRO NACIONAL DE PESQUISA EM ENSINO DE CIÊNCIAS, 4, 2003, Bauru. Atas... Bauru: ABRAPEC, 2003. 1 CD.

VILLANI, A. Conceptual change in science and science education. Science Education, New York, v. 76, n. 2, p. 223-237, april 1992.

VILLANI, A; CABRAL, T. C. B. Mudança conceitual, subjetividade e psicanálise. Investigações em Ensino de Ciências, Porto Alegre, v. 2, n. 1, p. 43-62, jan. 1997.

WANG, H. H. Why teach science? Graduate science students' perceived motivations for choosing teaching as a career in Taiwan. International Journal of Science Education, London, v. 26, n. 1, p. 113-128, jan. 2004.

WEINER, B. An attributional model of achievement motivation and emotion. Psychological Review, Washington, v. 92, n. 4, p. 548-573, Oct. 1985. 
WEINER, B. An attributional theory of motivation and emotion. New York: Springer, 1986. 304 p.

WEINER, B. Intrapersonal and interpersonal theories of motivation from an attributional perspective. Educational Psychology Review, New York, v. 12, n. 1, p. 1-14, may 2000 .

WATSON, D.; CLARK, L. A.; TELLEGEN, A. Development and validation of brief measures of positive and negative affect: the PANAS scale. Journal of Personality and Social Psychology, v. 54, n. 6, p. 1063-1070, 1988.

WOOLNOUGH, B. Effective science teaching. Buckingham: Open University Press, 1994.

\section{Apêndice 1}

\section{Questionário}

1) Quais motivos o levaram a fazer o curso de Licenciatura em Física (relação com o conhecimento)?

2) Havia algum assunto (fenômeno, tecnologia) que o intrigava durante o Ensino Médio?

"Lembro-me ainda hoje do meu primeiro dia de aula de ciências. Na escola pública que frequentava, ciências era uma disciplina ministrada na quinta série. Eu tinha 11 anos recém-feitos e guardo na memória os sentimentos de entusiasmo e alegria quando a professora nos contava que a matéria era constituída de átomos e moléculas. Não me recordo bem dos detalhes do conteúdo ensinado. Se ela apresentara a diferença entre gases e líquidos, ou se discutira sobre a água, o ar ou outra substância qualquer. Seria pedir muito à memória 30 anos depois. Porém, os sentimentos continuam vivos até hoje" (Um professor de Física).

3) $\mathrm{Na}$ sua história existe algo semelhante, uma explicação que fez sentido para você, isto é, deu certa satisfação (alegria) em conhecer? (cite mais de uma se houver). 